\title{
O Desafio de Redigir um Trabalho Acadêmico
}

\author{
The Challenge of Writing a Scholarly Work
}

El Reto de Escribir un Trabajo Académico

Isis Suruagy Correia Moura $^{1}$

A ciência busca a constatação de fatos e hipóteses, utilizando-se de teorias e métodos padronizados segundo os pares e os tempos. Relacionados a ela, e por ela apaixonados, estão os cientistas, que são aqueles que se esforçam para contribuir com seu desenvolvimento. O caminho da ciência em geral, se inicia na graduação quando o jovem estudante se depara com curiosidades sobre o mundo que aprende e se identifica com os mestres que se dedicam a desvendar problemas de pesquisas.

As Diretrizes Curriculares Nacionais (DCNs) que é um documento orientador para o desenvolvimento do projeto pedagógico e da gestão de um curso, geralmente trazem em seu bojo, a recomendação de que o aluno participe de programas de pesquisa, no sentido de ser introduzido neste fascinante mundo, aprendendo a realizar pesquisas e elaborar seus relatórios.

Importante também se torna a divulgação dos resultados das pesquisas, que normalmente acontece através da publicação de artigos científicos em periódicos específicos para cada tema e área.

O estudante, geralmente, se depara ao final do curso de graduação ou pós-graduação, com a obrigatoriedade de exprimir por escrito, e de forma cientifica, algum tema relacionado ao curso que conclui. Universidade Estácio de Sá. Mestre em Nutrição pela (UFAL). Doutora em Neuropsiquiatria e Ciência do Comportamento pela Universidade Federal de Pernambuco (UFPE). Nutricionista Clínica do Hospital das Clinicas da UFPE. Docente do Curso de Nutrição da Estácio. Autora correspondente: Rua Marquês de Marica, 12. Apt. 602. Torre. Recife - PE. Brasil. 50711-120. E-mail: isis_suruagy@yahooo.com.br 
Apesar de receber durante o percurso orientações especificas de como redigir um trabalho acadêmico, muita duvidas persistem, principalmente entre os mais novos, ou iniciantes na carreira acadêmica.

Ciente desta situação o Prof. Dr. Haroldo Miranda, da Universidade Federal de Alagoas, atuando na área da saúde, especificamente na Nutrição, sensível aos conflitos e problemas enfrentados por seus discentes, publica em 2011 o livro intitulado: Redação de Trabalhos Acadêmicos: nas Áreas das Ciências a Biológicas e da Saúde ${ }^{(1)}$.

O livro é resultado de textos produzidos pelo autor para disciplinas por ele lecionadas, apresenta-se composto por seis capítulos, três apêndices e dois anexos, resultando em 269 páginas de orientações e esclarecimentos sobre a produção de projetos de pesquisa, trabalho de conclusão de curso, dissertação, tese, artigo original e de revisão. Apresenta ainda, a normatização dos trabalhos segundo a Associação Brasileira de Normas Técnicas (ABNT) que é reconhecida pelo governo brasileiro para o estabelecimento de normas técnicas e nos casos dos artigos, expõe as recomendações constantes no Comitê
Internacional de Editores de Periódicos Médicos.

No primeiro capitulo o autor apresenta o Projeto de pesquisa, desde a seleção do Tema, até as normas gerais de sua formatação. Destaca que é importante motivar o aluno para a pesquisa, capacitando-o para tal, chamando a atenção para alguns fatores como: relevância do tema, infraestrutura disponível para execução da pesquisa e sobre o tempo para conclusão do trabalho.

Passa a discorrer sobre os Trabalhos de Conclusão de Curso (TCC) de estilo Monográfico no Capítulo 2, trazendo a estrutura do trabalho desde a capa até as referências, com a inclusão de figuras que auxiliam no entendimento da diagramação do texto. No Capítulo 3, traz o TCC E em forma de Artigo, quando apresenta as secções de um artigo cientifico, completando sobre o tema, oferecendo a estrutura e diretrizes para a elaboração do artigo cientifico, no Capítulo 5.

No Capítulo 4, encontramos os esclarecimentos referentes as citações e referências. $\mathrm{O}$ autor detalha o que é uma citação direta, indireta e citação de citação, trazendo as questões éticas necessárias para sua utilização. 
Foi no século $\mathrm{XX}$ que os computadores se firmaram como ferramenta de apoio aos investigadores científicos através de softwares de redação, tratamento estatístico e de bases de dados, promovendo a otimização do tempo principalmente no que se relaciona à bioestatística. Assim, finalmente no Capitulo 6, o autor traz as contribuições da informática a serviço da investigação cientifica, esclarecendo também sobre sites de busca de artigos publicados

Após leitura, uso e indicação, em nossa vida acadêmica, do texto ora resenhado, sentimos falta de uma discussão mais detalhada sobre questões éticas em pesquisa, como a análise e discussão de resolução sobre pesquisas com seres humanos, além da discussão do grave problema em pesquisa que é o plágio. $\mathrm{O}$ que deixamos aqui nossa sugestão ao autor.

Por tudo que foi exposto, recomendamos o livro para aqueles que se dedicam a pesquisa, quer seja docente, para indicação aos seus orientandos ou para própria consulta de forma rápida e fácil, quer seja um jovem estudante que se inicia neste belo e apaixonante caminho da pesquisa.

\section{Referência}

1. Ferreira H. Redação de Trabalhos Acadêmicos: nas Áreas das Ciências a Biológicas e da Saúde. Haroldo Ferreira. Rio de Janeiro: Rubio; 2011. 